Article

\title{
Effect of Ionic Liquid on the Determination of Aromatic Amines as Contaminants in Hair Dyes by Liquid Chromatography Coupled to Electrochemical Detection
}

\author{
Thiago Mescoloto Lizier and Maria Valnice Boldrin Zanoni * \\ Institute of Chemistry-State University “Julio de Mesquita Filho"-UNESP-Avenida Professor \\ Francisco Degni, 55, Quitandinha, CEP: 14800-900, Araraquara-SP, Brazil; \\ E-Mail: tmlizier@yahoo.com.br
}

* Author to whom correspondence should be addressed; E-Mail: boldrinv@yahoo.com.br; Tel.: +55-16-3301-9500; Fax: +55-16-3322-2308.

Received: 16 May 2012; in revised form: 24 June 2012 / Accepted: 25 June 2012 /

Published: 2 July 2012

\begin{abstract}
The room temperature ionic liquid (IL) 1-butyl-3-methylimidazolium bis-(trifluorometanesulfonyl)imide $\mathrm{BMIm}\left[\mathrm{NTf}_{2}\right]$ was used as a novel medium for improvement of separation and quantization of 16 aromatic amines typically present as contaminants in consumer products and detected by HPLC coupled to an electrochemical detector. The aromatic amines, namely 4,4'-diaminodiphenylmethane, 4-chloroaniline, 2-methoxy-5-methyl-aniline, 3,3'-dimethylbenzidine, 2,4-diaminotoluidine, 2-chloro-4nitroaniline, 4,4'-oxydianiline, aniline, 3,3'-dichlorobenzidine, benzidine, 4-aminobiphenyl, $o$-dianisidine, $o$-anisidine, $o$-toluidine, 4,4'-methylene-bis-2-chloroaniline and 2-naphthylamine are oxidized in methanol/BMIm[ $\left[\mathrm{NTf}_{2}\right]$ at a potential around $+0.68 \mathrm{~V}$ to $+0.93 \mathrm{~V} v s$. $\mathrm{Ag} / \mathrm{AgCl}$ at a glassy carbon electrode, which is the base for their determination by HPLC/ED. Using the optimized conditions of methanol/BMIm[NTf 2$] 70: 30(\mathrm{v} / \mathrm{v})$ as mobile phase, flow-rate of $0.8 \mathrm{~mL} \cdot \mathrm{min}^{-1}$, column CLC-ODS, $\mathrm{E}_{\mathrm{ap}}=+1.0 \mathrm{~V}$ and $\mathrm{T}=40{ }^{\circ} \mathrm{C}$ analytical curves were constructed for each of the tested amines. Good linearity was obtained in the concentration range of $1.09 \mathrm{mg} \cdot \mathrm{L}^{-1}$ to $217 \mathrm{mg} \cdot \mathrm{L}^{-1}$, with excellent correlation coefficients. The limits of detection reached $0.021 \mathrm{mg} \cdot \mathrm{L}^{-1}$ to $0.246 \mathrm{mg} \cdot \mathrm{L}^{-1}$ and good relative standard deviations $(\mathrm{RSD}, \mathrm{n}=3$ ) were obtained from the measurements. Satisfactory recovery for each aromatic amine was achieved, ranging from 95 to $103 \%$. The developed method was successfully applied to determine six aromatic amines present as contaminants in commercial hair dye samples.
\end{abstract}


Keywords: ionic liquid in chromatography; BMIm[NTf 2 ; HPLC with electrochemistry detection; hair dye; carcinogenic amines determination

\section{Introduction}

Aromatic amines are a class of chemicals essential in the plastic and chemical industries, and found as byproducts of the manufacture of compounds such as polyurethane foams, dyes, pesticides, pharmaceuticals and semiconductors. Aromatic amines can enter the aqueous environment as precursors from the synthesis of these compounds, via azo dye and nitroaromatic compound reductions [1,2], diesel exhaust, combustion of wood chips and rubber, tobacco smoke and grilled meats and fish and have been identified as potential carcinogens [3]. Since they have been designated as high priority pollutants, their presence in the environment must to be monitored at concentration levels lower than $30 \mathrm{mg} \cdot \mathrm{L}^{-1}$ compatible with the limits allowed by the regulations. Epidemiological evidence on the relation between aromatic amines and cancer risk has been reviewed [4]. In addition, the prohibition on the use of certain azo dyes that release one of the 22 aromatic amines as provided in EU Regulation (EC) 1907/2006 on the Registration, Evaluation and Authorization of Chemicals $(\mathrm{REACH})$, is directly applicable in all EU Member States. The main amines that are of great concern are: 4-aminobiphenyl, benzidine [4,4'-diaminobiphenyl], 4-chloro-o-toluidine [4-chloro-2-methylaniline], 2-napthylamine [2-aminonaphthalene], 4-chloroaniline, 4,4'-diaminodiphenylmethane [bis(4aminophenyl)methane], 3,3'-dichlorobenzidine [4-(4-amino-3-chlorophenyl)-2-chloroaniline], 3,3'dimethylbenzidine [4-(4-amino-3-methoxyphenyl)-2-methoxyaniline], o-dianisidine, 4,4'-methylenebis-(2-chloroaniline) [4-[(4-amino-3-chlorophenyl)methyl]-2-chloroaniline], 4,4'-oxydianiline, $o$-toluidine [2-methylaniline], o-anisidine [2-methoxyaniline], 2-methoxy-5-methylaniline, 2,4-diaminotoluidine [2,4-diaminotoluene], 2-chloro-4-nitroaniline, aniline [phenylamine]. Therefore, several methods are proposed in literature for analysis of aromatic amines.

In general, the amines condemned by the IARC are limited to ppb levels in natural waters, which demands sensitive analytical methods such as those based on electrochemical oxidation, spectrophotometric analysis after derivatization reactions, thin layer chromatography, gas chromatography, liquid chromatography with various types of detectors and capillary electrophoresis [5-14].

The literature also describes examples for the determination of aromatic amines in environmental samples [15-18], foods [19,20], biological fluids [21-23] and from treatments leading to partial degradation of azo dyes [24-29]. As a disadvantage, they have high detection limits and need long pre-concentration processes for a good sensitivity, and derivatization processes to enhance the volatility of these amines when analyzed by gas chromatography, for instance. The high basicity, reactivity and polar nature of aromatic amines are responsible for different problems involved on the extraction and detection by chromatographic analysis [1]. The coupling of electrochemical detectors (ED) in High Performance Liquid Chromatography (HPLC) systems has shown great potential in the quantification of trace organic compounds in various matrices [30]. The method presents higher sensitivity than other conventional methods and raised some problems such as lack of baseline stabilization and adsorption of oxidized species from substrate or impurities onto the electrode surface. 
The separation of amine compounds at HPLC-ED condition still remains problematic due to the interactions with silanol groups in the chromatography columns.

The special characteristics of room temperature ionic liquids (IL) for electrochemical applications have been the focus of several researchers [31-33]. They are robust compounds that present good conductivity, exhibit wide electrochemical potential windows [29,30] and, as materials composed of cations and anions, are able to solvate a large variety of organic and inorganic compounds, either polar or non-polar. In addition, some authors have used ionic liquids as mobile phase additives to improve the detection and separation of amines by liquid chromatography [34,35]. Usually, ionic liquids can compete for the silanol groups of stationary phase with the basic groups of the analytes and no polar alkyl groups of the stationary phase can interact with different alkyl groups of the heterocyclic ring or quaternary cation of the IL [36]. The ion-paring with cationic solutes [37] could efficiently shield the residual silanols, which should improve the peak shapes while reducing the chromatographic retention times of the basic analytes [38]. The high conductivity of some ionic liquids also removes the need for other supporting electrolytes and allow for a higher potential window necessary to oxidize the aromatic amines [39-43]. Martin-Calero [44] showed the beneficial effects of several ionic liquids (ILs) as mobile phase additives in high-performance liquid chromatography with electrochemical detection for determination of heterocyclic aromatic amines (HAs) in food samples.

The aim of the present work was to develop an sensitive analytical method for the determination of 16 aromatic amines condemned by IARC and found in commercial hair dyes using high liquid chromatography coupled to an electrochemical detector by using the ionic liquid 1-butyl-3methylimidazolium bis(trifluoromethanesulfonyl)imide $\left(\mathrm{BMIm}\left[\mathrm{NTf}_{2}\right]\right)$ in the mobile phase.

\section{Results and Discussion}

\subsection{Cyclic Voltammetric Investigations}

In order to optimize the experimental conditions required in the development of an electrochemical detection system previously the voltammetric oxidation of amines of interest on glassy carbon electrode in a methanol/ionic liquid medium was investigated. Cyclic voltammograms were recorded for each one of the 16 aromatic amines. Figure 1 shows the cyclic voltammograms obtained for oxidation of $244 \mathrm{mg} \cdot \mathrm{L}^{-1} o$-dianisidine in 50:50 methanol/ionic liquid where the ionic liquid was 1-butyl-3-methylimidazolium bis(trifluoromethylsulfonyl)imide (BMIm[NTf $\left.{ }_{2}\right]$ ), 1-butyl-3-methylimidazolium tetrafluoroborate $\left(\mathrm{BMIm}\left[\mathrm{BF}_{4}\right]\right)$ or 1-hexyl-3-methylimidazolium hexafluorophosphate (HMIm[PF 6 ). The voltammetric behaviors of the chosen model compound were similar in all cases. The oxidation in $\mathrm{BMIm}_{-} \mathrm{BF}_{4}$ presents one peak at $0.93 \mathrm{~V}$, attributed to the oxidation of the amine. In $\mathrm{HMIm}\left[\mathrm{PF}_{6}\right]$ the $o$-dianisidine is also oxidized in one step at $0.71 \mathrm{~V}$ and in BMIm[NTf 2 its oxidation occurs at $+0.91 \mathrm{~V}$, respectively. This electrochemical behavior is slightly different in relation to the supporting electrolyte methanol/ $\mathrm{LiCl}\left(4.2 \mathrm{~g} \cdot \mathrm{L}^{-1}\right)$ where two anodic peaks at $+0.49 \mathrm{~V}$ and $+0.62 \mathrm{~V}$ and two cathodic peaks at $+0.55 \mathrm{~V}$ and $+0.43 \mathrm{~V}$ are observed, indicating that the amine group is probably oxidized in two steps of two electron transfer [45]. 
Figure 1. Cyclic voltammogram obtained for oxidation of $244 \mathrm{mg} \cdot \mathrm{L}^{-1}$ of $o$-dianisidine in $4.2 \mathrm{~g} \cdot \mathrm{L}^{-1}$ of $\mathrm{LiCl}(\mathrm{I})$; $o$-dianisidine in $12.6 \mathrm{mg} \cdot \mathrm{L}^{-1}$ of $\mathrm{BMIm}\left[\mathrm{NTf}_{2}\right]$ (II); $o$-dianisidine in $6.78 \mathrm{mg} \cdot \mathrm{L}^{-1} \mathrm{BMIm}\left[\mathrm{BF}_{4}\right](\mathrm{III})$; o-dianisidine in $\left.9.36 \mathrm{mg} \mathrm{L}{ }^{-1} \mathrm{HMIm}_{\mathrm{PF}}\right]$ (IV) at a glassy carbon electrode. Scan speed $(\mathrm{v})=50 \mathrm{mV} \cdot \mathrm{s}^{-1}$.

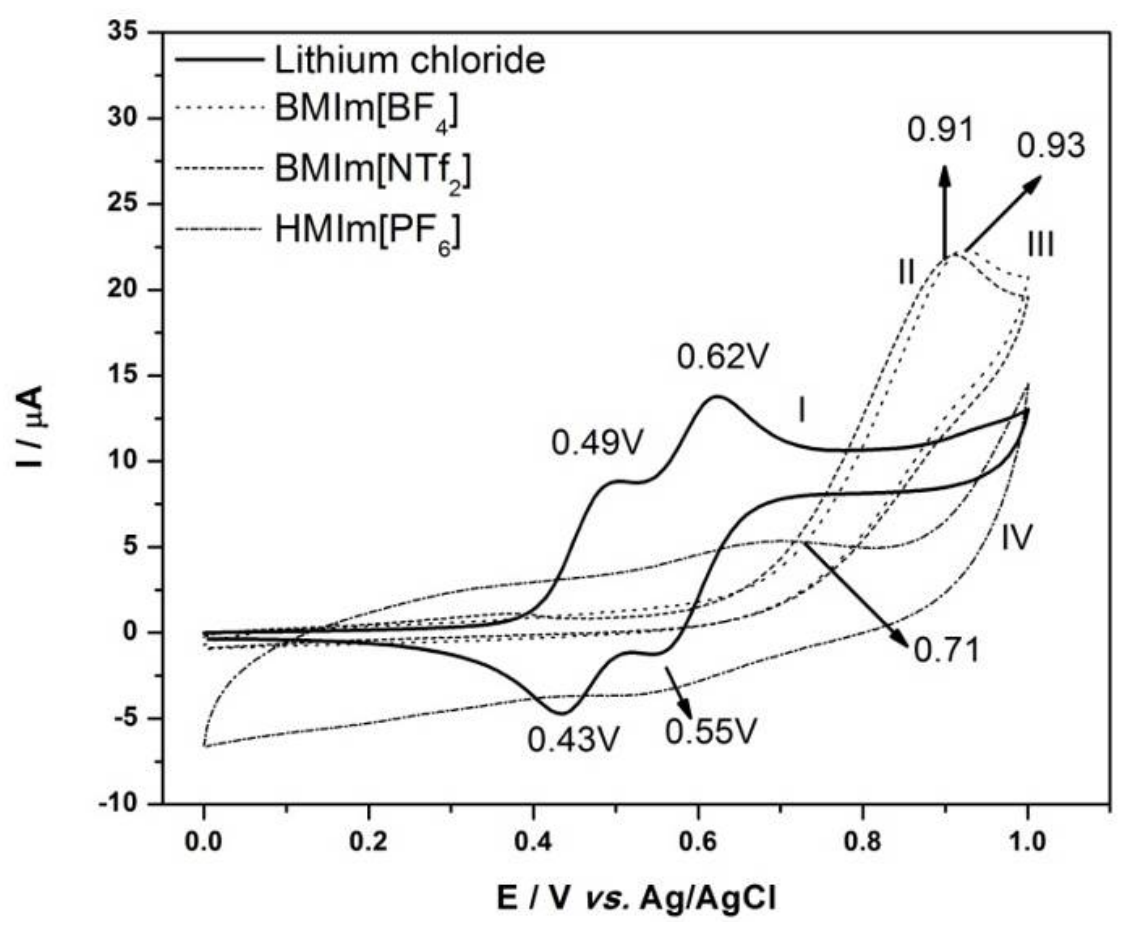

In IL the first peak is much smaller than the main peak around $0.66 \mathrm{~V}$ to $0.72 \mathrm{~V}$, but in the $\mathrm{LiCl}$ it is inexistent. This behavior indicates that in $\mathrm{HMIm}\left[\mathrm{PF}_{6}\right]$ ionic liquid $o$-dianisidine probably forms an ionic pair with the anion of the IL, leading to formation of a pre-peak at less positive potential where the amine group is oxidized, however from $\mathrm{BMIm}\left[\mathrm{BF}_{4}\right]$ and $\mathrm{BMIm}\left[\mathrm{NTf}_{2}\right]$ ionic liquid no ionic pair forms, leading to formation of a more positive peak from the oxidation of the amine group. Taking into consideration the form and position of the peaks in the voltammogram methanol/BMIm[NTf $\left.\mathrm{N}_{2}\right]$ was chosen the as the best supporting electrolyte for further studies.

The cyclic voltammograms obtained for $244 \mathrm{mg} \cdot \mathrm{L}^{-1}$ of aromatic amines in methanol/BMIm[NTf ${ }_{2}$ ] (50:50) are shown in Figure 2. It is possible to observe the occurrence of two oxidation steps for the following amines: benzidine, 3,3'-dimethylbenzidine, 4,4'-oxydianiline, 4-chloroaniline and aniline. In contrast, only one oxidation step is observed for: $o$-anisidine, $o$-toluidine, 4,4'-methylene-bischloroaniline, 2-napthylamine, 4,4'-diaminodiphenylmethane, 2-methoxy-5-methylaniline, 2,4diaminotoluidine, 2-chloro-4-nitroaniline, 4-aminobiphenyl, with no peak in the cathodic scan. A linear relationship is obtained for plots of peak currents $\left(\mathrm{II}_{\mathrm{c}}\right) v s$. square-root scan rate. 
Figure 2. Cyclic voltammogram obtained for oxidation of $244 \mathrm{mg} \cdot \mathrm{L}^{-1}$ of amine in the ionic liquid BMIm[NTf $\left.f_{2}\right]$ at a glassy carbon electrode. Scan speed: $50 \mathrm{mV} \cdot \mathrm{s}^{-1}$. (A) 2,4diaminotoluidine; (B) 2-chloro-4-nitroaniline; (C) 2-methoxy-5-methylaniline; (D) 2naphtylamine; (E) 3,3'-dichlorobenzidine; (F) 3,3'-dimethylbenzidine; (G) 4,4'-diaminodiphenylmethane; (H) 4,4'-methylene-bis-chloroaniline; (I) 4,4'-oxydianiline; (J) 4-aminobiphenyl; (K) 4-chloroaniline; (L) aniline; (M) benzidine; (N) $o$-anisidine; $(\mathbf{O}) o$-toluidine in (I) amine + methanol $/ 0.1 \mathrm{~mol} \cdot \mathrm{L}^{-1}$ of Lithium chloride; (II) amine + methanol/BMIm[BF 4 ] (50:50 v/v); (III) amine + methanol/BMIm[NTf 2$](50: 50 \mathrm{v} / \mathrm{v}) ;(\mathrm{IV})$ amine + methanol/HMIm $\left[\mathrm{PF}_{6}\right](50: 50 \mathrm{v} / \mathrm{v})$ at glassy carbon electrode. Scan rate $=50 \mathrm{mV} \cdot \mathrm{s}^{-1}$.

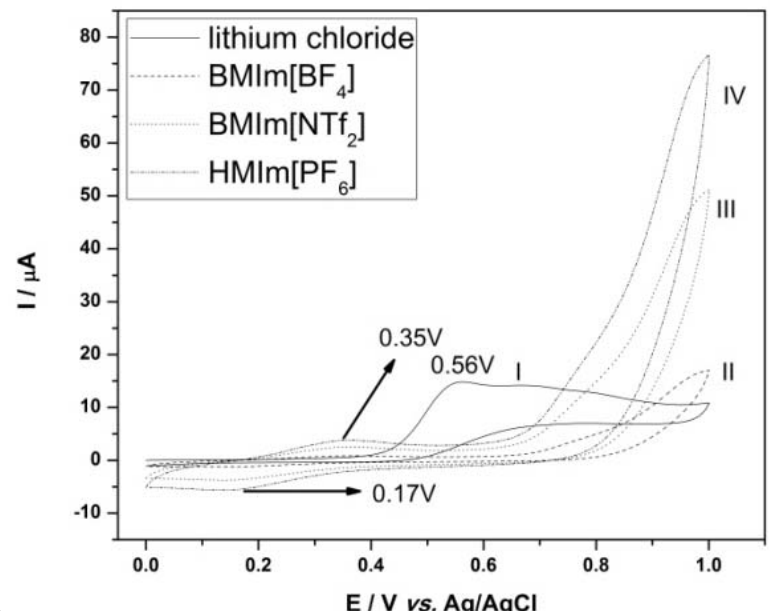

A

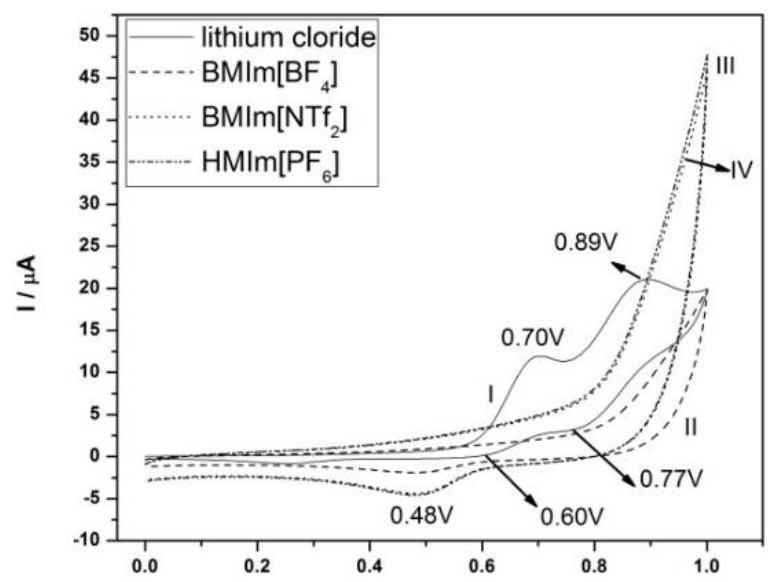

C

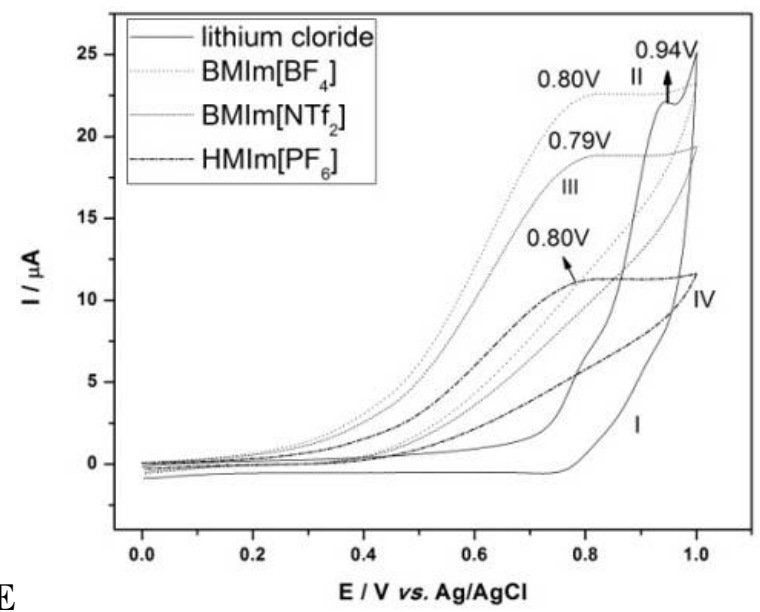

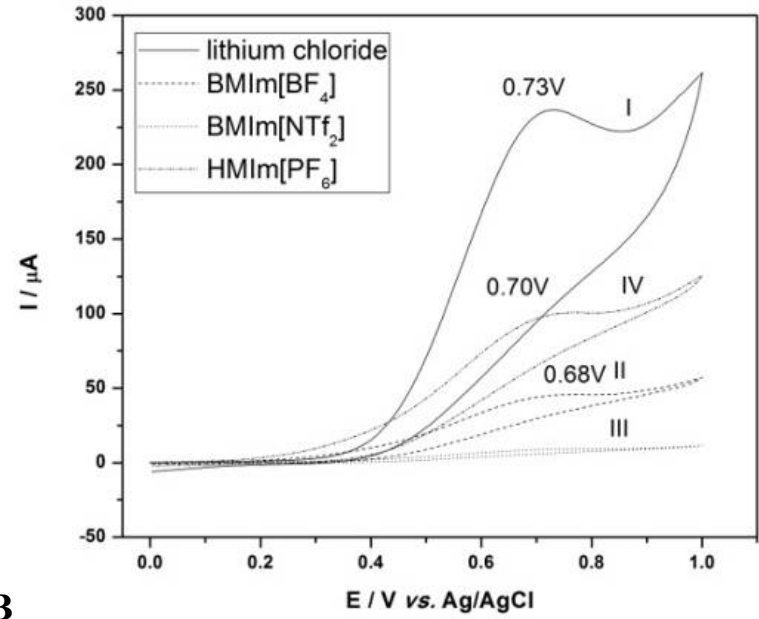

B

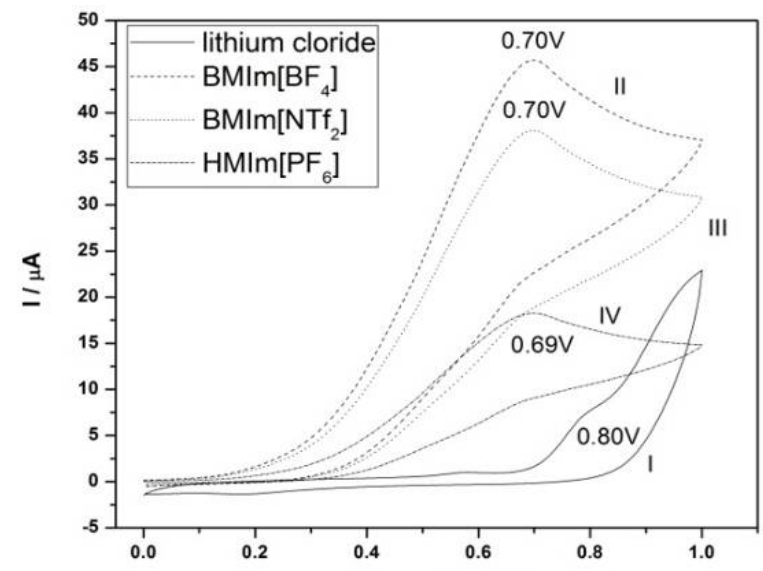

D

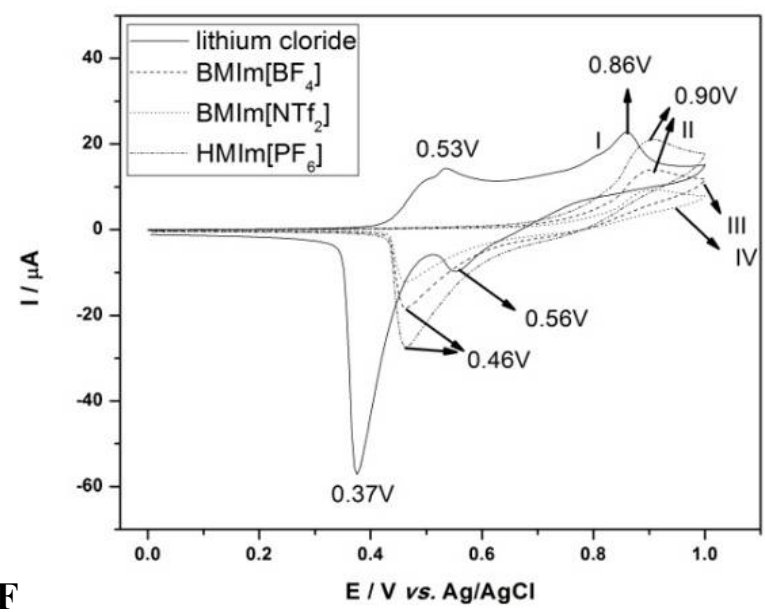


Figure 2. Cont.

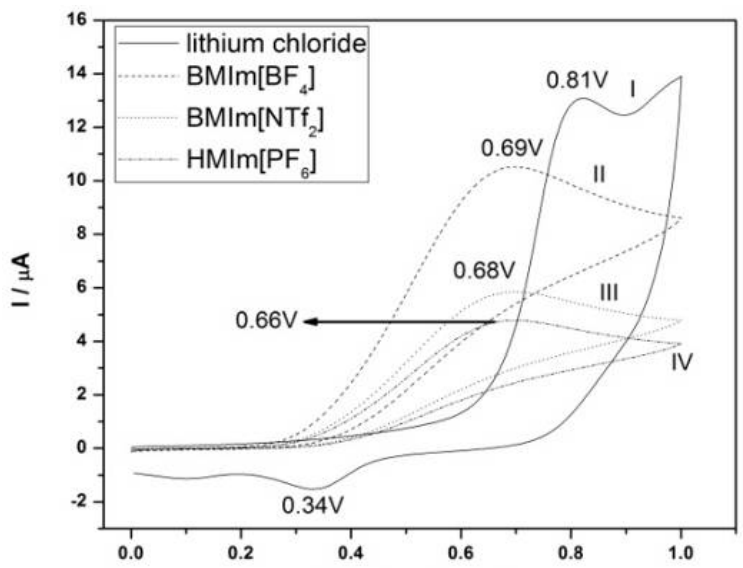

G

$\mathrm{E} / \mathrm{V}$ vs. $\mathrm{Ag} / \mathrm{AgCl}$
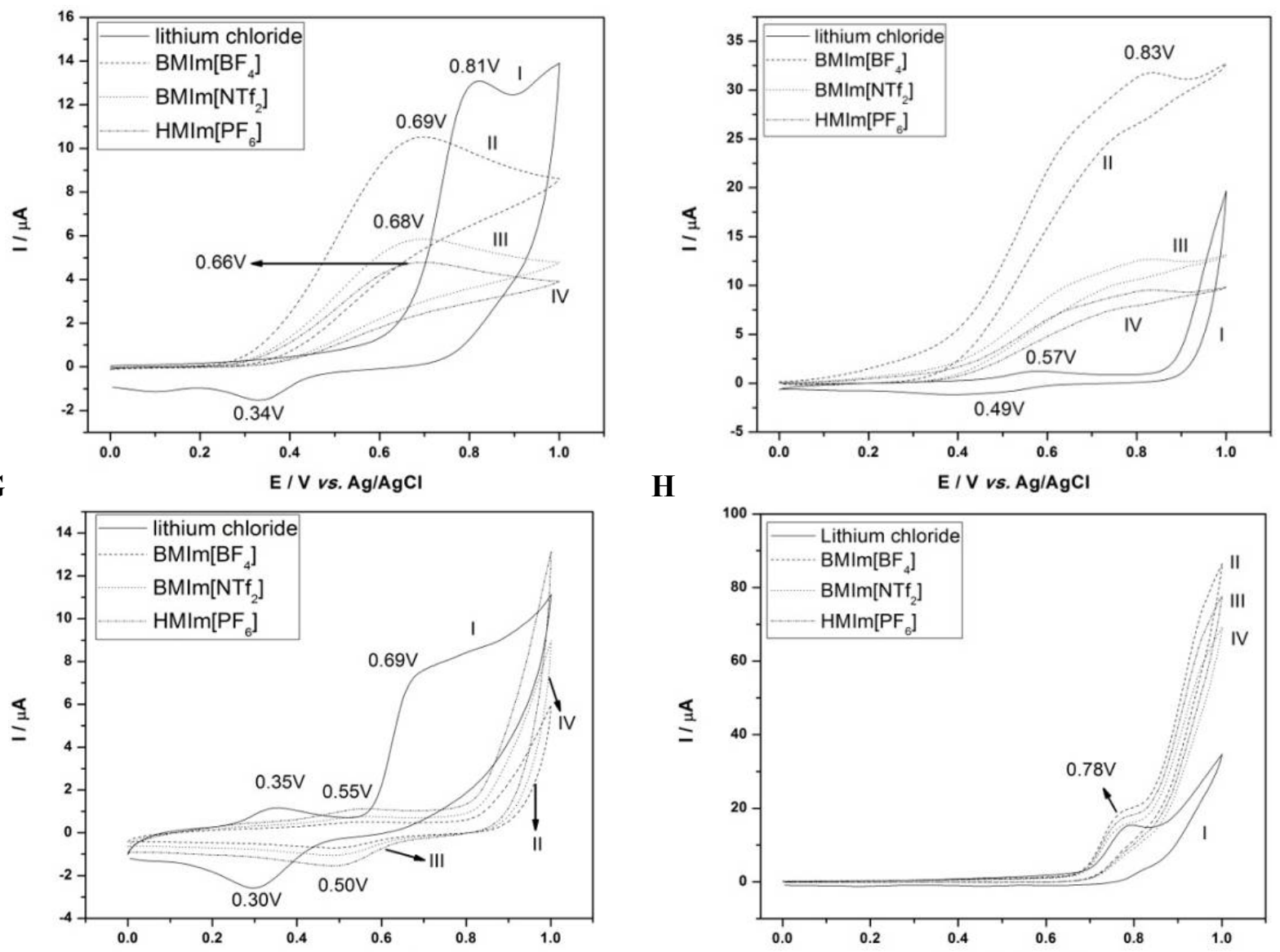

H

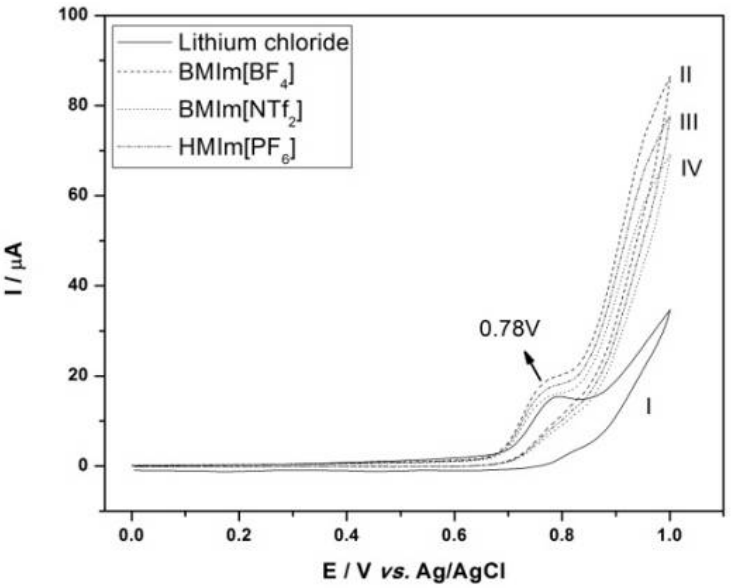

I

$\mathrm{E} / \mathrm{V}$ vs. Ag/AgCl

J

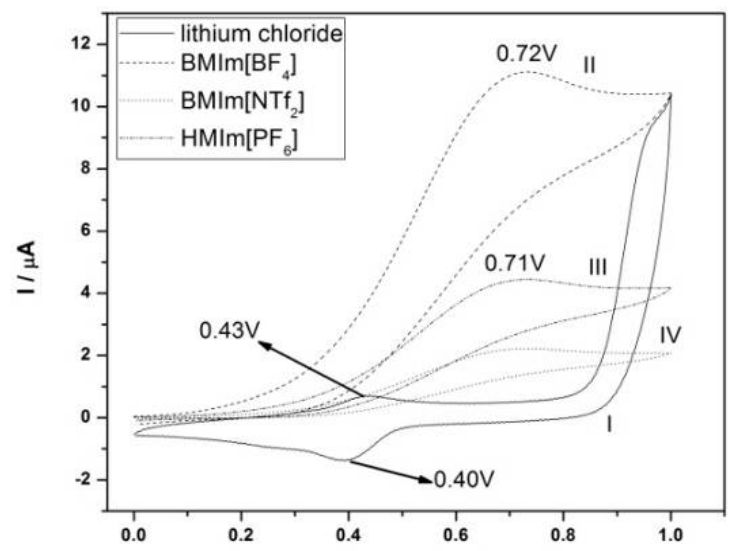

K

$\mathrm{E} / \mathrm{V}$ vs. Ag/AgCl

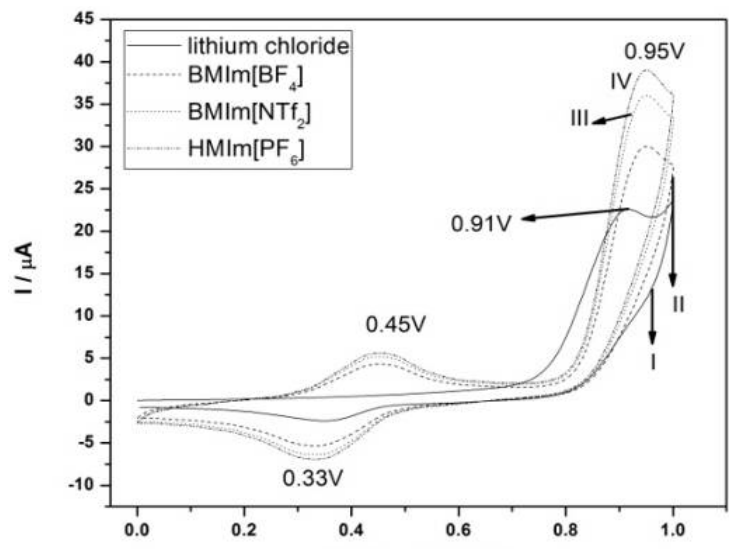

L

$\mathrm{E} / \mathrm{V}$ vs. Ag/AgCl
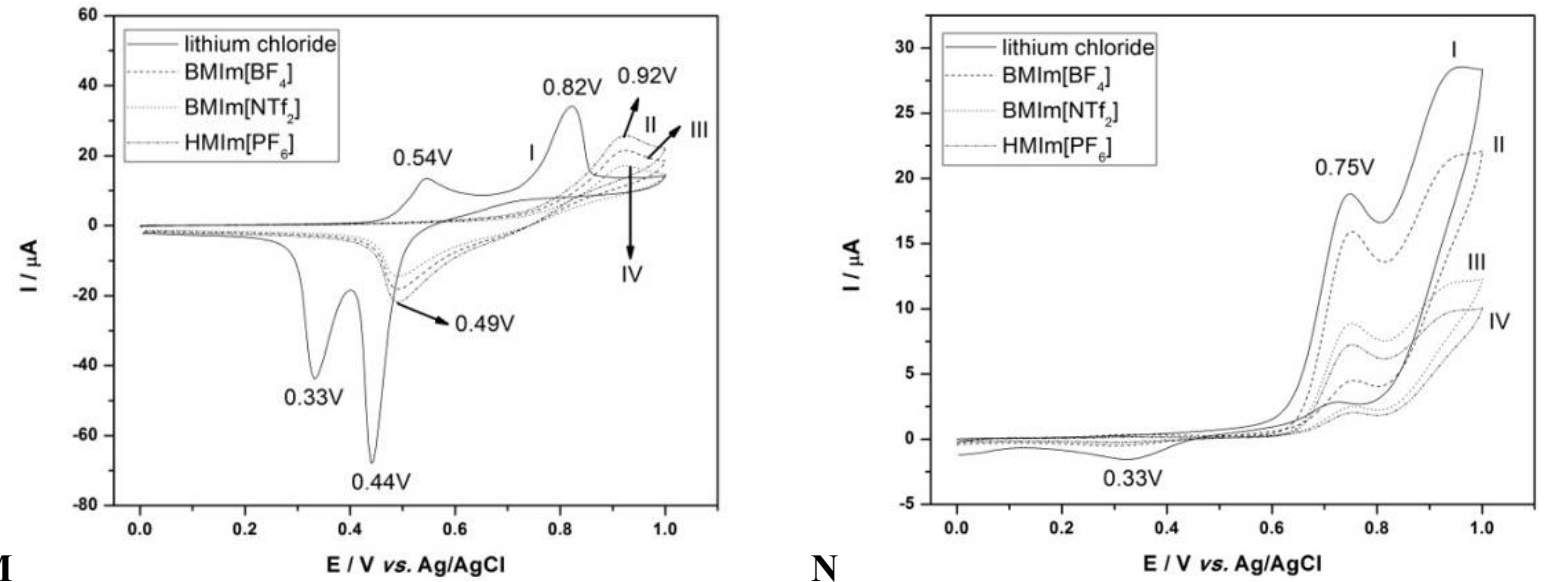
Figure 2. Cont.

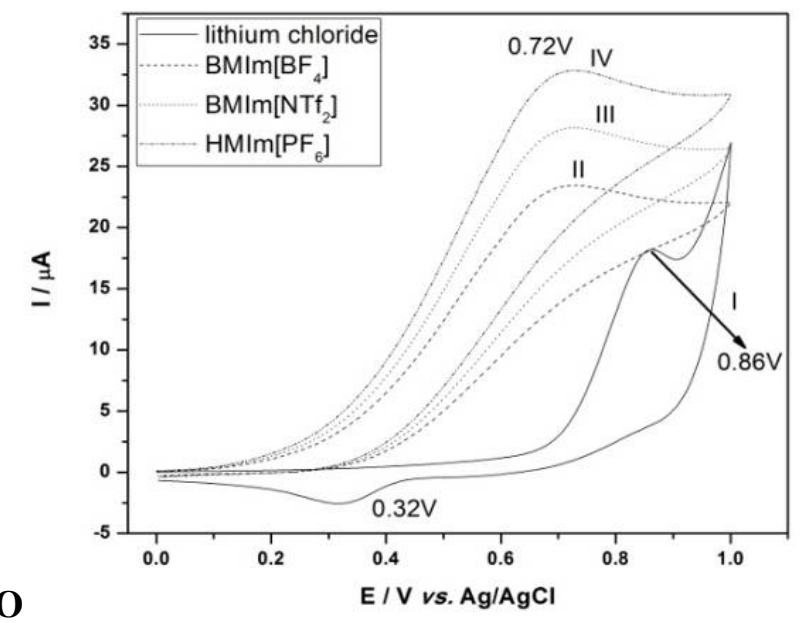

The Table 1 shows the potential and peak currents from the anodic scan. This behavior indicates that all anodic processes are diffusion controlled and could be used to detect the aromatic amines by HPLC/ED.

Table 1. Voltammetric parameters obtained for oxidation of aromatic amines at glassy carbon electrode at $50 \mathrm{mV} \cdot \mathrm{s}^{-1}$ in methanol/lithium cloride and methanol/BMIm[NTf $\mathrm{NT}_{2}$.

\begin{tabular}{|c|c|c|c|c|c|c|c|c|}
\hline \multirow[b]{2}{*}{ Amine compounds } & \multicolumn{4}{|c|}{ LiCl } & \multicolumn{4}{|c|}{$\operatorname{BMIm}\left[\mathbf{N T f}_{2}\right]$} \\
\hline & $\begin{array}{l}E_{a 1} \\
(V)\end{array}$ & $\begin{array}{l}E_{a_{2}} \\
(V)\end{array}$ & $\begin{array}{l}I p_{a} \mathbf{I} \\
(\mu \mathrm{A})\end{array}$ & $\begin{array}{l}\mathbf{I} p_{\mathrm{a} I I} \\
(\boldsymbol{\mu} \mathbf{A})\end{array}$ & $\begin{array}{l}E_{a 1} \\
(V) \\
\end{array}$ & $\begin{array}{l}E_{a 2} \\
(V) \\
\end{array}$ & $\begin{array}{l}I p_{\mathrm{a}} \mathrm{I} \\
(\mu \mathrm{A})\end{array}$ & $\begin{array}{l}\mathbf{I} \mathbf{p}_{\mathrm{c} \text { II }} \\
(\boldsymbol{\mu} \mathbf{A})\end{array}$ \\
\hline 2,4-Diaminotoluidine & +0.56 & -- & 15.6 & -- & -- & 0.90 & -- & -- \\
\hline 2-Chloro-4-nitroaniline & +0.73 & -- & 12.8 & -- & +0.68 & -- & 18.6 & -- \\
\hline 2-Methoxy-5-methylaniline & +0.70 & +0.89 & 10.3 & 8.9 & -- & 0.91 & -- & -- \\
\hline 2-Naphthylamine & +0.80 & -- & 14.5 & -- & +0.70 & -- & 16.5 & -- \\
\hline 3,3'-Dimethylbenzidine & +0.53 & +0.86 & 11.4 & 12.3 & +0.46 & +0.90 & 12.3 & 10.4 \\
\hline 4,4'-Diaminodiphenylmethane & +0.81 & - & 13.5 & -- & +0.68 & -- & 16.8 & -- \\
\hline 4,4'-Methylene-bis-chloroaniline & +0.57 & - & 9.3 & & -- & +0.85 & -- & -- \\
\hline 4,4'-Oxydianiline & +0.35 & +0.69 & 6.7 & 6.2 & +0.55 & +0.50 & 6.2 & 6.8 \\
\hline 4-Aminobiphenyl & +0.78 & -- & 9.8 & -- & +0.78 & -- & 9.1 & -- \\
\hline 4-Chloroaniline & +0.43 & -- & 8.6 & & +0.71 & -- & 12.8 & -- \\
\hline Aniline & +0.91 & -- & 9.6 & -- & +0.45 & 0.95 & 10.3 & 14.4 \\
\hline Benzidine & +0.54 & +0.82 & 10.3 & 13.2 & +0.92 & -- & 12.4 & \\
\hline$o$-Anisidine & +0.75 & -- & 9.1 & -- & +0.75 & -- & 10.2 & -- \\
\hline$o$-Dianisidine & +0.49 & +0.62 & 14.4 & 14.8 & +0.93 & -- & 15.2 & -- \\
\hline$o$-Toluidine & +0.86 & -- & 12.8 & -- & +0.72 & -- & 14.2 & -- \\
\hline
\end{tabular}

These results indicate that all the aromatic amines investigated presented an amine group oxidized at a potential from $0.45 \mathrm{~V}$ to $0.93 \mathrm{~V}$, which could be the basis for its selective amperometric detection when coupled to HPLC. 


\subsection{HPLC/ED Optimizations}

\subsubsection{Optimization of Mobile Phases}

The development of an analytical method for aromatic amine determination based on HPLC/ED was first investigated testing the parameters concentration of solvent and concentration of ionic liquid in the mobile phase, flow rate, applied potential and type of solvent. The composition and concentration of the supporting electrolyte are known to have a marked influence on the electrochemical detection response [44]. For this, several supporting electrolytes using methanol/water $+0.1 \%$ formic acid and Acetonitrile/water $+0.1 \%$ of formic acid varied from 60:40 (v/v); 70:30 (v/v); 80:20 (v/v) and 85:15 (v/v). Using some chromatographic parameters such as retention time, resolution, it was concluded that the best conditions for separation of the investigated compounds were obtained for methanol/water $+0.1 \%$ of formic acid 70:30 (v/v). In order to improve the peak resolution in the chromatograms of aromatic amines, the influence of mobile phase flow-rate through the column was investigated comparing chromatograms recorded from 0.6 to $1.2 \mathrm{~mL} \cdot \mathrm{min}^{-1}$. The flow rate can be an important parameter to optimize the analysis, since the flow-rate variations lead to significant changes in the column efficiency, thereby affecting the number of theoretical plates $(\mathrm{N})$ in the column. The results obtained indicate that an upper limit of flow-rate of $1.2 \mathrm{~mL} \cdot \mathrm{min}^{-1}$ can be used, since higher flow-rates cause excessive column pressure usually limited to $350 \mathrm{Kgf}$. Flow-rates lower than $0.6 \mathrm{~mL} \cdot \mathrm{min}^{-1}$ result in separation times longer than $40 \mathrm{~min}$, which were considered unacceptable for this methodology. In order to avoid these anomalies, the chromatograms were recorded using a careful polish of the working electrode surface before each increase in the flow-rate, through a clean electrochemistry program set changing from $+1.0 \mathrm{~V}$ to $-1.0 \mathrm{~V}$ during $10 \mathrm{~s}$. Using these experimental conditions, a flow-rate of $0.80 \mathrm{~mL} \cdot \mathrm{min}^{-1}$ was considered as the optimum value for the resolutions in the chromatogram with excellent repeatability.

An electrochemical detector requires the application of a potential high enough to oxidize all the aromatic amines give a high response, but not so high as to compete with the supporting electrolyte discharge. Thus, taking into consideration the voltammograms obtained under static conditions the detector was configured to work in amperometric mode from $+0.50 \mathrm{~V}$ to $+1.2 \mathrm{~V}$. For this, curves of current $v s$. potential were constructed for each amine $\left(24 \mathrm{mg} \cdot \mathrm{L}^{-1}\right)$ in methanol/LiCl $\left(4.23 \mathrm{~g} \cdot \mathrm{L}^{-1}\right)$ in proportion $70: 30 \mathrm{v} / \mathrm{v}$ as mobile phase, at a flow-rate of $0.80 \mathrm{~mL} \cdot \mathrm{min}^{-1}$.

Figure 3 shows the current curves obtained as a function of applied potential for the investigated aromatic amines. The analysis of Figure 3 indicates that higher peak intensities are observed for applied potentials $\left(\mathrm{E}_{\mathrm{o}}\right)$ from $1.0 \mathrm{~V}$. Therefore, an applied potential value of $+1.0 \mathrm{~V}$ was chosen as optimum to detect all amines. 
Figure 3. Hydrodynamic voltammograms of a $24 \mathrm{mg} \cdot \mathrm{L}^{-1}$ standard of a: 4,4'-oxydianiline; b: aniline; c: 2,4-diaminotoluidine; d: $o$-dianisidine; e: benzidine; f: 4,4'-methylene-bis-(2chloroaniline); g: 2-naphthylamine; h: $o$-toluidine; i: $o$-anisidine; j: 4,4'-diaminodiphenylmethane; $\mathbf{k}$ : 3,3'-dimethylbenzidine; l: 2-chloro-4-nitroaniline; $\mathbf{m}$ : 4-aminobiphenyl; n: 2-methoxy-5-methylaniline; o: 4-chloroaniline; p: 3,3'-dichlorobenzidine solution at HPLC coupled to an electrochemical detector (glassy carbon electrode). Mobile phase: methanol/water $70: 30(\mathrm{v} / \mathrm{v})+0.1 \%$ formic acid; Flow-rate: $0.8 \mathrm{~mL} \cdot \mathrm{min}^{-1}$; Column: Shimpack (Shimadzu) CLC-ODS; T: $40{ }^{\circ} \mathrm{C}$.

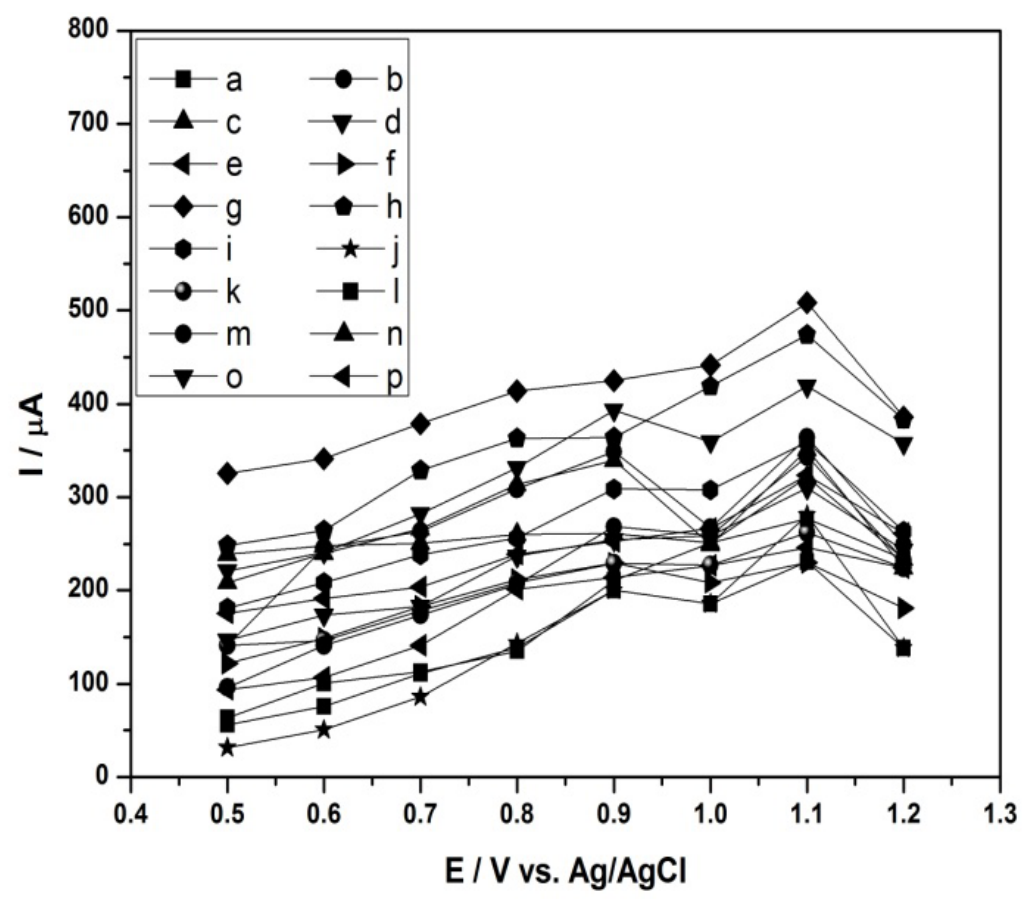

Figure 4 shows a typical chromatogram for standard solutions of $24 \mathrm{mg} \cdot \mathrm{L}^{-1}$ of amine in methanol/LiCl $\left(4.23 \mathrm{~g} \cdot \mathrm{L}^{-1}\right)$ in proportion $70: 30 \mathrm{v} / \mathrm{v}$ as mobile phase and a flow-rate of $0.80 \mathrm{~mL} \cdot \mathrm{min}^{-1}$, $\mathrm{E}_{\text {oxid }}=+1.0 \mathrm{~V}$ for each aromatic amines. The elution of the examined compounds was completed in a time of $25 \mathrm{~min}$ during a chromatographic run. Peak identifications were based on their retention times, which were confirmed comparing with standard samples of the aromatic amines and gave the following sequence: 4,4'-diaminodiphenylmethane (6.48 $\mathrm{min})$; 4-chloroaniline (7.42 $\mathrm{min})$; 2-methoxy-5-methylaniline (8.61 min); 3,3'-dimethylbenzidine (9.09 $\mathrm{min})$; 2,4-diaminotoluidine (10.6 $\mathrm{min})$; 2-chloro-4-nitroaniline (11.30 min); 4,4'-oxydianiline (11.30 $\mathrm{min})$; aniline (12.43 $\mathrm{min})$; 3,3'dichloro-benzidine (13.60 $\mathrm{min}$ ); benzidine (15.97 $\mathrm{min}$ ); 4-aminobiphenyl (16.53 $\mathrm{min}$ ); o-dianisidine (17.40 min); $o$-anisidine (17.95 $\mathrm{min})$; $o$-toluidine (18.59 $\mathrm{min}) ; 4,4$ '-methylene-bis-2-chloroaniline (20.41 $\mathrm{min})$; 2-naphtylamine (21.44 $\mathrm{min})$. From this chromatogram is possible to observe that no separation of the peaks corresponding to 2-chloro-4-nitroaniline $(11.30 \mathrm{~min})$ and 4,4'-oxydianiline (11.30 $\mathrm{min}$ ) was obtained. In addition, there is peak broadening, leading to poorer analytical performance. 
Figure 4. HPLC/ED chromatograms obtained for $20 \mu \mathrm{L}$ of standard solution of $24 \mathrm{mg} \cdot \mathrm{L}^{-1}$ of the selected amines. Mobile phase: $\mathrm{MeOH} /$ water $+0.1 \%$ formic acid 70:30 (v/v) $\mathrm{T}=40{ }^{\circ} \mathrm{C}$, flow $=0.80 \mathrm{~mL} \cdot \mathrm{min}^{-1} ; \mathrm{C}_{18}$ phase column, $\mathrm{E}=+1.00 \mathrm{~V} . \mathbf{1}: 4,4$ '-diaminodiphenyl-methane; 2: 4-chloroaniline; 3: 2-methoxy-5-methylaniline; 4: 3,3'-dimethylbenzidine; 5: 2,4diamintoluidine; 6: 2-chloro-4-nitroaniline; 7: 4,4'-oxydianiline; 8: aniline; 9: 3,3'dichlorobenzidine; 10: benzidine; 11: 4-aminobiphenyl; 12: $o$-dianisidine; 13: $o$-anisidine; 14: $o$-toluidine; 15: 4,4'-methylene-bis-2-chloroaniline; 16: 2-naphthylamine.

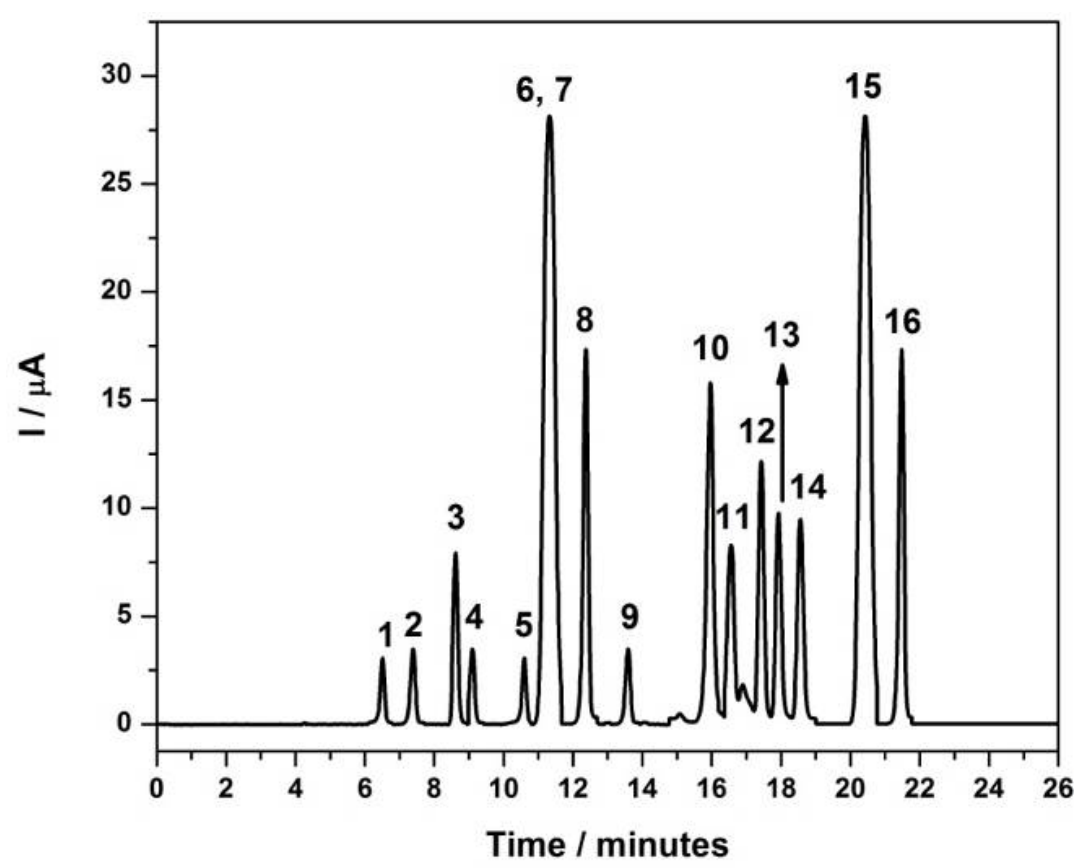

Theoretically, the conversion efficiency of a thin-layer amperometric cell, as used in this study, could be improved by decreasing the flow rate through the cell, thereby increasing the residence time of the analyte in contact with the working electrode, but all the experiments show unsatisfactory results.

\subsubsection{Separation of Aromatic Amines After Addition of BMIm[NTf $\left.\mathrm{N}_{2}\right]$ in the Mobile Phase}

With the aim to increase the resolution of these peaks further studies were carried out on solutions of the 16 aromatic amines in methanol/water in proportion $70: 30+12.6 \mathrm{mg} \cdot \mathrm{L}^{-1} \mathrm{BMIm}\left[\mathrm{NTf}_{2}\right]$. The concentration of the ionic liquid constituent is known to have a marked influence on the electrochemical detection response [46]. For this, cyclic voltammograms were recorded comparing three ionic liquids in methanol/water varying the concentration from $4.22 \mathrm{mg} \cdot \mathrm{L}^{-1}$ to $12.6 \mathrm{mg} \cdot \mathrm{L}^{-1}$. The ionic liquid $\mathrm{HMIm}\left[\mathrm{PF}_{6}\right]$ did not show sufficient solubility in water. The ionic liquid $\mathrm{BMIm}\left[\mathrm{BF}_{4}\right]$ showed no significant effect on the resolution and peak height. Thus, the ionic liquid BMIm[NTf $\left.{ }_{2}\right]$ presented best voltammograms, in addition better curves were obtained using $12.6 \mathrm{mg} \cdot \mathrm{L}^{-1}$. Hydrodynamic voltammograms constructed using current $v s$. potential for each amine $\left(24 \mathrm{mg} \cdot \mathrm{L}^{-1}\right)$ in methanol/water $+12.6 \mathrm{mg} \cdot \mathrm{L}^{-1} \mathrm{BMIm}\left[\mathrm{NTf}_{2}\right]$ in proportion $70: 30 \mathrm{v} / \mathrm{v}$ as mobile phase, and a flow-rate of $0.80 \mathrm{~mL} \cdot \mathrm{min}^{-1}$ are shown in Figure 5 . 
Figure 5. Hydrodynamic voltammograms of a $24 \mathrm{mg} \cdot \mathrm{L}^{-1}$ standard of: a: 4,4'-oxydianiline; b: aniline; c: 2,4-diaminotoluidine; d: $o$-dianisidine; e: benzidine; f: 4,4'-methylene-bis-(2chloroaniline); g: 2-naphthylamine; h: $o$-toluidine; i: $o$-anisidine; j: 4,4'-diaminodiphenylmethane; k: 3,3'-dimethylbenzidine; l: 2-chloro-4-nitroaniline; m: 4-aminobiphenyl; n: 2-methoxy-5-methylaniline; o: 4-chloroaniline; p: 3,3'-dichlorobenzidine solution at HPLC coupled to an electrochemical detector (glassy carbon electrode). Mobile phase: methanol/water 70:30 (v/v) $+12.6 \mathrm{mg} \cdot \mathrm{L}^{-1}$ BMIm [NTf ${ }_{2}$. Flow-rate: $0.8 \mathrm{~mL} \cdot \mathrm{min}^{-1}$. Column: Shimpack (Shimadzu) CLC-ODS; T: $40{ }^{\circ} \mathrm{C}$.

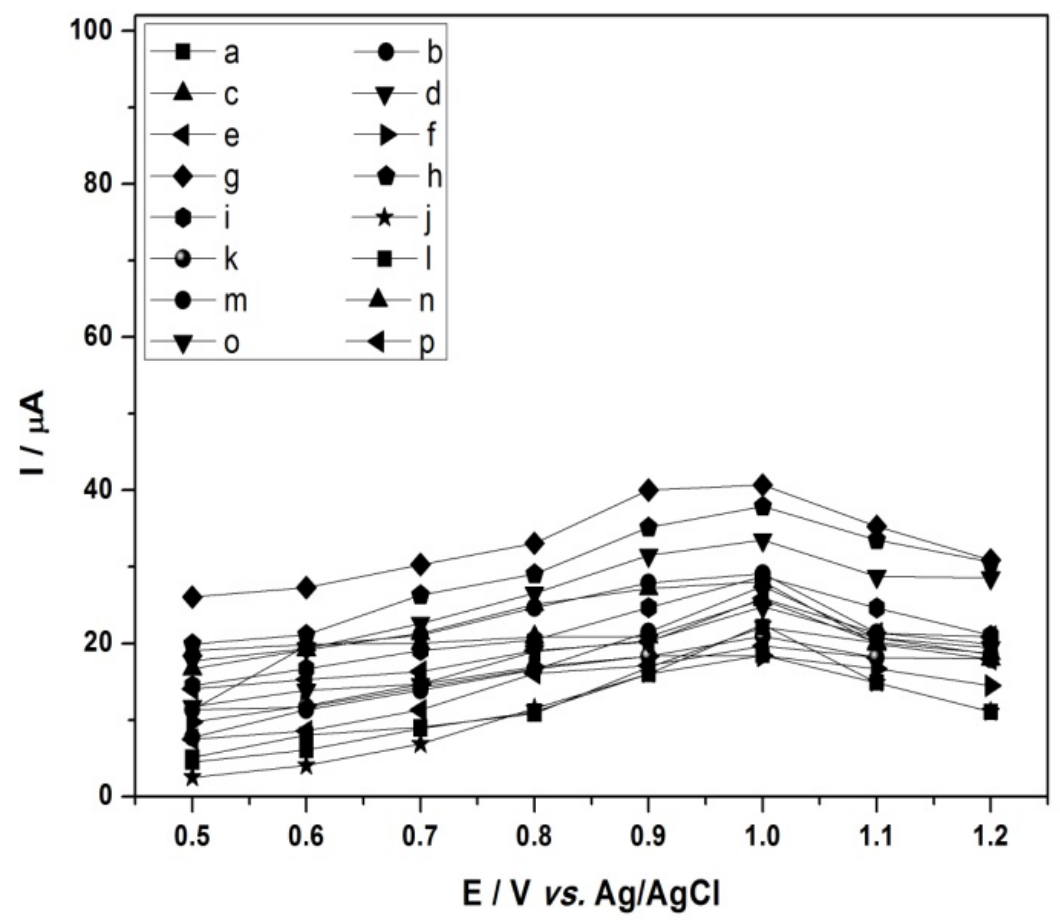

Figure 5 shows the obtained curves of current in function of applied potential for the investigated aromatic amines. It indicates that higher peak intensities are observed for applied potentials $\left(\mathrm{E}_{\mathrm{o}}\right)$ from 0.90 to $1.0 \mathrm{~V}$. Therefore, an applied potential value of $+1.0 \mathrm{~V}$ was chosen the optimum one which can promote the most selective response and high sensitivity to detect all amines using the proposed method.

A typical chromatogram for a mixture of standard solutions containing $24 \mathrm{mg} \cdot \mathrm{L}^{-1}$ of aromatic amines of electrochemical detection using the best conditions, previously: flow-rate of $0.8 \mathrm{~mL} \cdot \mathrm{min}^{-1}$, methanol/water $+30 \mathrm{mmol} \cdot \mathrm{L}^{-1} \mathrm{BMIm}\left[\mathrm{NTf}_{2}\right] ;(70: 30 \mathrm{v} / \mathrm{v}), \mathrm{E}_{\mathrm{ox}}=+1.0 \mathrm{~V}$ is shown in Figure 6.

The retention times were found to become slightly different in the presence of liquid ionic, following the sequence: 4,4'-diaminodiphenylmethane (4.7 $\mathrm{min}) ; 3,3^{\prime}$-dimethylbenzidine (5.3 $\left.\mathrm{min}\right)$; 2-methoxy-5-methylaniline (6.1 $\mathrm{min})$; 4-chloroaniline (6.7 $\mathrm{min})$; 2,4-diaminotoluidine (7.2 $\mathrm{min})$; 2-chloro-4-nitroaniline (8.6 $\mathrm{min}) ; 4$ 4'-oxydianiline (10.6 $\mathrm{min})$; 4-aminobiphenyl (12.6 $\mathrm{min})$; 3,3'-dichlorobenzidine (13.4 min); benzidine (13.8 min); aniline (15.1 min); o-dianisidine (15.9 min); $o$-anisidine $(17.3 \mathrm{~min})$; o-toluidine (18.7 $\mathrm{min})$; 2-naphthylamine (20.1 $\mathrm{min})$; 4,4'-methylene-bis-2chloroaniline $(21.7 \mathrm{~min})$. The elution of the examined compounds was completed in a time of 22 min during a chromatographic run. Peak identifications were based on their retention times, which were compared with the peaks from chromatograms of the standard solutions of all aromatic amines investigated. 
Figure 6. HPLC/ED chromatograms obtained for $20 \mathrm{~mL}$ of standard solution of $24 \mathrm{mg} \cdot \mathrm{L}^{-1}$ of the selected amines. Mobile phase: $\mathrm{MeOH} /$ water $+30 \mathrm{mM} \mathrm{BMIm}\left[\mathrm{NTf}_{2}\right]$ 70:30 (v/v); T: $40{ }^{\circ} \mathrm{C}$, flow-rate: $0.80 \mathrm{~mL} \cdot \mathrm{min}^{-1} ; \mathrm{C}_{18}$ phase column, E: $+1.00 \mathrm{~V}$. 1: 4,4'-diaminodiphenylmethane; 2: 3,3'-dimethylbenzidine; 3: 2-methoxy-5-methylaniline; 4: 4-chloroaniline; 5: 2,4-diaminotoluidine; 6: 2-chloro-4-nitroaniline; 7: 4,4'-oxydianiline; 8: 4-aminobiphenyl; 9: 3,3'-dichlorobenzidine; 10: benzidine; 11: aniline; 12: $o$-dianisidine; 13: $o$-anisidine; 14: $o$-toluidine; 15: 2-naphthylamine; 16: 4,4'-methylene-bis-2-chloroaniline.

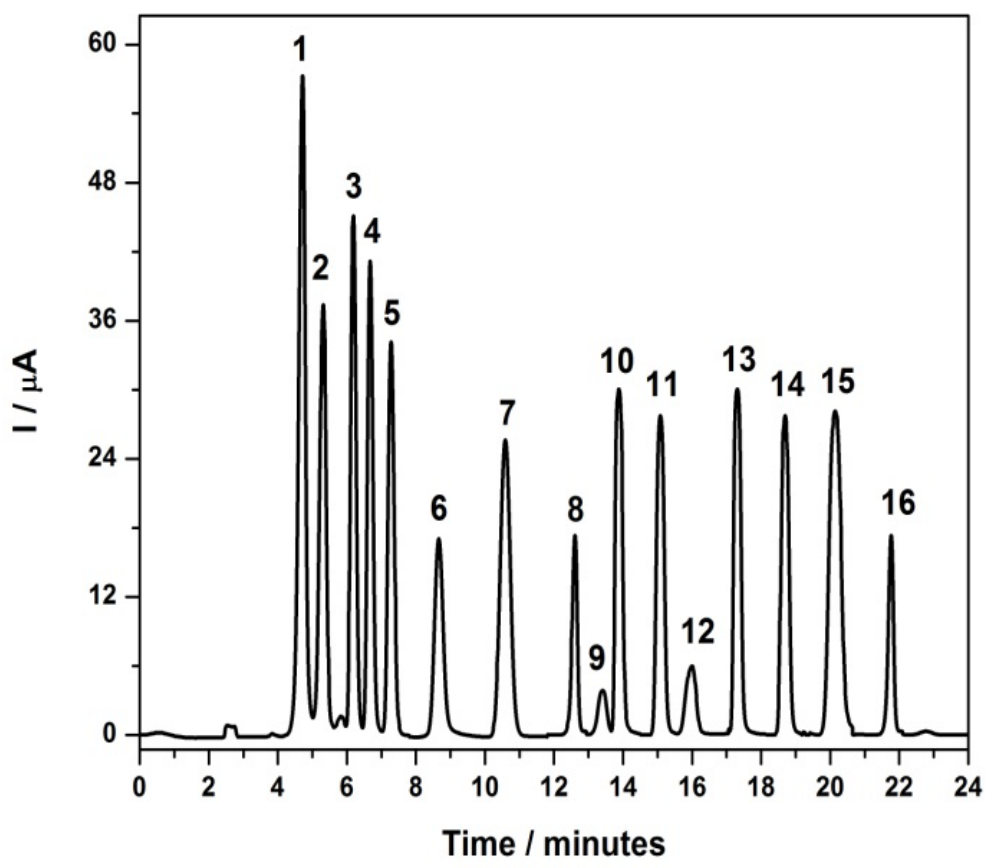

The results indicated that the addition of the soluble liquid ionic $\mathrm{BMIm}\left[\mathrm{NTf}_{2}\right]$ in water gives a great improvement in the resolution, peak height and shape of the chromatographic peaks since these are dependent on the kinetic interaction between the silanol groups of the stationary phase of the column and the analytes. The vast majority of the aromatic amines are positively charged under the experimental conditions, which causes strong interactions with the residual silanols of the chromatographic column that are negatively charged. The addition of ionic liquid in the mobile phase causes a blocking of the silanols interaction reducing the peak broadening. The ionic liquid cations are mostly responsible for these interactions with the stationary phase silanol groups. In addition, the cations of the IL can form ionic pairs with the aromatic amines and decrease their adsorption on the electrode surface which usually disturbs the baseline. These combined effects influence the separation mechanisms occurring on the stationary phase, decreases the retention times of the amines and alters the elution order when comparing with the analysis performed in the absence of the ionic liquid.

The results thus indicate that ionic liquids can play an important role in the analysis of aromatic amines by HPLC/ED. The strong proton-acceptor properties of these IL can be utilized to suppress the deleterious effects of free silanols on liquid chromatographic separations. The chaotropic character of the anion may introduce ion-pairing with cationic solutes and adsorption on the stationary phase. The hydrophobicity of the cation may further induce stationary phase adsorption. All these factors in combination offer a simple way to detect aromatic amines at low level. 


\subsubsection{Analytical Curves}

The analytical HPLC/ED curves based on the relation of peak area and concentration were preferred instead of peak height for all the 16 aromatic amines in order to eliminate the possible effects of species adsorbed on the electrode surface, which could prejudice the quantitative response. The analytical curves for each aromatic amine were constructed by plotting the peak area against the concentration and a linear range was obtained from $1.09 \mathrm{mg} \cdot \mathrm{L}^{-1}$ to $217 \mathrm{mg} \cdot \mathrm{L}^{-1}$ (Table 2).

Table 2. Analytical parameters HPLC/ED from 16 aromatic amines, flow rate: $0.8 \mathrm{~mL} \cdot \mathrm{min}^{-1}$, mobile phase: methanol/water $+12.64 \mathrm{mg} \cdot \mathrm{L}^{-1}$ of $\mathrm{BMIm}\left[\mathrm{NTf}_{2}\right], \mathrm{E}=+1.0 \mathrm{~V}$.

\begin{tabular}{|c|c|c|c|c|c|c|c|c|c|c|c|c|}
\hline \multirow{2}{*}{ Amines } & \multirow{2}{*}{$\mathbf{A} * *$} & \multirow{2}{*}{$\mathbf{B} * * *$} & \multirow{2}{*}{$\mathbf{N}$} & \multirow{2}{*}{$\mathbf{R}$} & \multirow{2}{*}{ SD } & \multirow{2}{*}{ L.O.D. } & \multirow{2}{*}{ L.O.Q. } & \multicolumn{2}{|c|}{ As } & \multicolumn{2}{|c|}{ Np } & \multirow{2}{*}{ Rec. } \\
\hline & & & & & & & & 1 & 2 & 1 & 2 & \\
\hline 2,4-Diaminotoluidine & 4350.89 & 2035.16 & 5 & 0.998 & 686.0 & 0.110 & 0.337 & 0.85 & 0.92 & 31211.1 & 9421.9 & 100 \\
\hline 4,4'-Oxydianiline & 16596.20 & 2424.22 & 6 & 0.993 & 795.6 & 0.108 & 0.328 & -- & 0.90 & 6491.8 & 5842.1 & 98 \\
\hline Benzidine & 24.50 & 70.04 & 6 & 0.997 & 26.13 & 0.123 & 0.374 & 0.84 & 0.96 & 24214.4 & 22548.7 & 97 \\
\hline$o$-Dianisidine & 7178.19 & 1813.43 & 6 & 0.997 & 597.8 & 0.303 & 0.113 & 0.80 & 0.94 & 190096.0 & 31604.9 & 100 \\
\hline o-Anisidine & -8505.88 & 2230.6 & 6 & 0.998 & 680.3 & 0.103 & 0.303 & 0.77 & 0.96 & 89301.4 & 56808.3 & 103 \\
\hline$o$-Toluidine & 26373.5 & 2049.62 & 6 & 0.997 & 651.4 & 0.091 & 0.276 & 0.82 & 0.95 & 95378.0 & 66528.4 & 100 \\
\hline 2-Naphthylamine & 48572.45 & 4245.71 & 6 & 0.999 & 128.7 & 0.101 & 0.305 & 0.78 & 0.98 & 127925.4 & 45033.3 & 103 \\
\hline 4,4'-Methylene-bis-2-chloroaniline & 4549.79 & 1818.46 & 6 & 0.998 & 695.8 & 0.126 & 0.382 & 0.81 & 0.97 & 28985.1 & 156528.1 & 100 \\
\hline 3,3'-Dimethylbenzidine & -753.02 & 250.09 & 9 & 0.997 & 162.5 & 0.021 & 0.638 & 0.78 & 0.99 & 22901.8 & 4956.2 & 95 \\
\hline 2-Methoxy-5-methyl-aniline & 317.02 & 81.64 & 9 & 0.999 & 88.5 & 0.036 & 1.078 & 0.78 & 0.95 & 20544.4 & 6833.8 & 100 \\
\hline 4-Chloroaniline & -108.03 & 72.00 & 9 & 0.997 & 26.6 & 0.120 & 0.368 & 0.76 & 0.98 & 39151.2 & 7932.9 & 105 \\
\hline 2-Chloro-4-nitroaniline & -342.46 & 196.29 & 9 & 0.999 & 82.8 & 0.163 & 0.495 & -- & 0.96 & 6491.8 & 9216.7 & 98 \\
\hline 4-Aminobiphenyl & 433.67 & 166.55 & 9 & 0.999 & 82.9 & 0.162 & 0.497 & 0.79 & 0.98 & 42642.2 & 52399.4 & 97 \\
\hline 3,3'-Dichlorobenzidine & -339.63 & 464.56 & 9 & 0.999 & 120.6 & 0.246 & 2.021 & 0.81 & 0.96 & 51680.4 & 34110.3 & 96 \\
\hline
\end{tabular}

L.O.D.: detection limited $\left(\mathrm{mg} \cdot \mathrm{L}^{-1}\right)$; L.O.Q.: quantification limited $\left(\mathrm{mg} \cdot \mathrm{L}^{-1}\right) . * *$ linear coefficient; *** slope; \# standard deviation; N: number of measures; R: correlation coefficient; As: symmetric (1: without IL; 2:with IL); Np: number of theory plates (1: without IL; 2:with IL) ; Rec.: Recovery.

\subsection{Evaluation of Aromatic Amines in Commercial Dyeing Sample}

The accuracy and recovery of the method were determined by spiking water samples with aromatic amine standards at a concentration level of $24 \mathrm{mg} \cdot \mathrm{L}^{-1}$, whereby the samples were filtered through Millipore MILLEX filters and injected immediately. Extractions and analyses were performed in triplicate. The results obtained by the standard addition method or comparing calibration curves are shown in Table 1. Recoveries ranging from 95 to 105\% of aromatic amines were obtained using the proposed method. This is a good evidence of the accuracy of the proposed method.

The direct analysis of the aromatic amines in a commercial samples of hair dyes was not possible, since there is great interference of compounds in the sample in the background signal, but the chromatograms obtained under optimized condition after sample clean-up (Section 3.2.3) showed good performance and the HPLC/ED can be more sensitive. The method was applied to commercial dyes and indicated the occurrence of six amines (Figure 7), identified as 4,4'-diaminodiphenylmethane 
(5.21 $\left.\mathrm{mg} \cdot \mathrm{L}^{-1}\right), 2$,4-diaminotoluidine $\left(4.32 \mathrm{mg} \cdot \mathrm{L}^{-1}\right), 4,4^{\prime}$-oxydianiline $\left(39.6 \mathrm{mg} \cdot \mathrm{L}^{-1}\right)$, 4-aminobiphenyl $\left(5.07 \mathrm{mg} \cdot \mathrm{L}^{-1}\right)$, aniline $\left(9.95 \mathrm{mg} \cdot \mathrm{L}^{-1}\right)$ and 4,4'-methylene-bis-2-chloroaniline $\left(4.567 \mathrm{mg} \cdot \mathrm{L}^{-1}\right)$. It may be noted that various amines were found in the product formulation in the commercial dyes, but only 4,4'-oxydianiline was present in a higher concentration than permitted. This shows the danger that users and especially beauty professionals and cosmetologists run in contact with these compounds because they can cause cancer and other health problems.

Figure 7. HPLC/ED chromatograms obtained for $20 \mu \mathrm{L}$ of commercial solution of hair dye sample. Mobile phase: $\mathrm{MeOH} /$ water $+30 \mathrm{mM} \mathrm{BMIm}\left[\mathrm{NTf}_{2}\right]$ 70:30 (v/v) T: $40{ }^{\circ} \mathrm{C}$, flow-rate: $0.80 \mathrm{~mL} \cdot \mathrm{min}^{-1} ; \mathrm{C}_{18}$ phase column, $\mathrm{E}=+1.00 \mathrm{~V} .1$ : 4 ,4-diaminodiphenylmetame; 2: 2,4-diaminotoluidine; 3: 4,4'-oxydianiline; 4: 4-aminobiphenyl; 5: aniline; 6 : 4,4'-methylene-bis-2-chloroaniline.

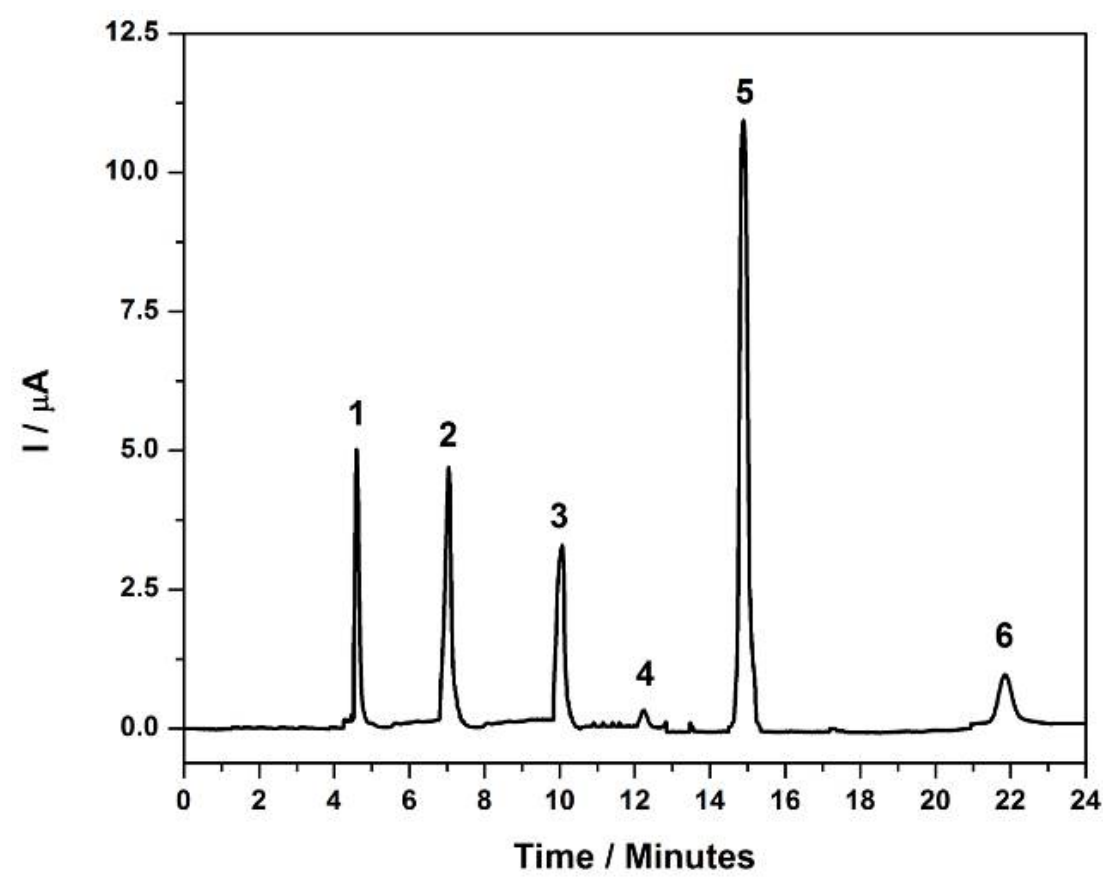

\section{Experimental}

\subsection{Reagents}

The studied amines were 2-naphthylamine (98\%), 4,4'-methylene-bis-(2-chloroaniline) (85\%), aniline (99\%), o-toluidine (98\%), 4,4'-oxidianiline (98\%), o-dianisidine (98\%), $o$-anisidine (99\%), 3,3'-dimethylbenzidine (97\%), 2-methoxy-5-methylaniline (99\%) and 4-aminobiphenyl (90\%) purchased from Sigma-Aldrich. 2,4-diaminotoluidine (98\%), benzidine (98\%), 4,4'-diamino-bisphenylmethane (97\%), 4-chloroaniline (99\%) and 2-chloro-4-nitroaniline (98\%) purchased from Fluka. 3,3'-Dichlorobenzidine (99\%) purchased from Supelco. Stock standard solutions in methanol containing $50 \mathrm{mg} \cdot \mathrm{L}^{-1}$ were prepared. These solutions were kept refrigerated at $0{ }^{\circ} \mathrm{C}$ and protected from light. Dilutions were made from stock solutions as needed. All samples were filtered through a Millex filter. The ionic liquids 1-butyl-3-methylimidazolium bis(trifluorometanesulfonyl)imide (BMIm[NTf 2$]$ ), 1-butyl-3-methylimidazolium tetrafluoroborate $\left(\mathrm{BMIm}\left[\mathrm{BF}_{4}\right]\right)$, and 1-hexyl-3-methylimidazolium 
hexafluorophosphate $\left.\left(\mathrm{HMIm}_{\mathrm{PF}}\right]\right)$, were purchased from Sigma-Aldrich. Acetonitrile and methanol were of HPLC-grade supplied by J.T. Baker. Water was purified using a Milli-Q system from Millipore.

\subsection{Instrumentation}

\subsubsection{Voltammetric Analysis}

Voltammetric measurements were performed using a PGSAT 30 potentiostat/galvanostat with a conventional three electrode arrangement. A glassy carbon electrode ( $2.5 \mathrm{~mm}$ diameter) was utilized as working electrode, the reference electrode was of $\mathrm{Ag} / \mathrm{AgCl}$ and a $\mathrm{Pt}$ wire was the counter electrode. The glassy carbon electrode was polished with $1 \mu \mathrm{m}$ alumina slurries on lapping pads. All the voltammograms were recorded after $5 \mathrm{~s}$ equilibration time and at a scan rate of $50 \mathrm{mV} \cdot \mathrm{s}^{-1}$. The samples were prepared dissolving $244 \mathrm{mg} \cdot \mathrm{L}^{-1}$ the aromatic amines in $10 \mathrm{~mL}$ methanol $/ \mathrm{LiCl} 0.1 \mathrm{~mol} \cdot \mathrm{L}^{-1}$ or in $10 \mu \mathrm{L}$ of methanol/ionic liquid that were mixed until completely homogeneous. All solutions were purged with high purity nitrogen for 10 min prior to recording the voltammograms, and a continuous stream of nitrogen was passed over the solutions during measurements.

\subsubsection{HPLC Analysis}

All the HPLC analysis coupled to an electrochemical detector was carried out using a Metrohm System 871 advanced Bioscan, with a 818 IC pump. Data acquisition and process were accomplished with an IC Net Workstation (Metrohm, Herisau, Switzerland). The separation was performed on a Phenomenex Luna $\mathrm{C}_{18}$ column $(250 \mathrm{~mm} \times 4.6 \mathrm{~mm}, 5 \mu \mathrm{m}$ particle size $)$ and a Shimadzu pre-column. A Metrohm Bioscan electrochemical cell was used, where the glassy carbon electrode is inserted as working electrode, a Variocell reference electrode with solid-phase $\mathrm{Ag} / \mathrm{AgCl}$ and $\mathrm{Pt}$ as counter electrode. The aromatic amines were separated using methanol/ionic liquids or methanol/LiCl. All samples were filtered before each injection using Millex Millipore filters ( $0.45 \mu \mathrm{m})$. Ionic liquids are obtained from Sigma-Aldrich.

\subsubsection{Analysis of Dyes in the Commercial Sample}

The occurrence of aromatic amines was tested in a commercial hair dye sample assigned code HF 65, from ARIANOR. The following procedure was adopted: in a separatory funnel was added $3.00 \mathrm{~mL}$ of the commercial sample dissolved in $3.00 \mathrm{~mL}$ of dichloromethane (in triplicate). The organic phase rich in aromatic amine was evaporated and then dissolved in methanol. The samples were filtered through a $0.45 \mu \mathrm{m}$ MILLEX filter and injected into the HPLC using the procedure described previously.

\section{Conclusions}

There is a strong consumer demand for hair dyes and for new analytical methods that identify and quantify these dyes. Our findings indicate that the use of room temperature ionic liquids as mobilephase additives in high performance liquid chromatography (HPLC) offers great advantages in the separation of a wide variety of carcinogenic amines, especially using electrochemical detection. The method based on HPLC/ED has been shown here as being capable of determining very low levels of 
carcinogenic amines in hair dyes by using methanol/water + $\mathrm{BMIm}\left[\mathrm{NTf}_{2}\right](70: 30 \mathrm{v} / \mathrm{v})$ as mobile phase. Even, at low concentrations in mobile phases, the anions and cations of the ionic liquid dramatically affect the retention times and resolution of the target compounds. Our findings provide a fast and simple method for the analysis of amines as contaminants in hair dye products using a very simple pretreatment step. The proposed method is suggested as a good alternative for the routine quality control of this type of dyes in different matrices demanding quick and low cost analysis.

\section{Acknowledgments}

The authors thank FAPESP, CNPq and CAPES for the financial support of this work.

\section{References}

1. Akyüz, M.; Ata, S. Determination of aromatic amines in hair dye and henna samples by ion-pair extraction and gas chromatography-mass spectrometry. J. Pharm. Biomed. Anal. 2008, 47, 68-80.

2. Lloret, S.M.; Legua, C.M.; Falco, P.C. Preconcentration and dansylation of aliphatic amines using C-18 solid-phase packings-Application to the screening analysis in environmental water samples. J. Chromatogr. A 2002, 978, 59-69.

3. Possanzini, M.; Palo, V.D. Improved HPLC determination of Aliphatic-Amines in air by diffusion and derivatization techniques. Chromatographia 1990, 29, 151-160.

4. Vineis, P.; Pirastu, R. Aromatic amines and cancer. Cancer Causes Control 1997, 8, 346-355.

5. Wang, S.P.; Huang, T.H. Separation and determination of aminophenols and phenylenediamines by liquid chromatography and micellar electrokinetic capillary chromatography. Anal. Chim. Acta 2005, 534, 207-214.

6. Zhou, J.; Xu, H.; Wan, G.H.; Duan, C.F.; Cui, H. Enhancing and inhibiting effects of aromatic compounds on luminol-dimethylsulfoxide- $\mathrm{OH}$-chemiluminescence and determination of intermediates in oxidative hair dyes by HPLC with chemiluminescence detection. Talanta 2004, 64, 467-477.

7. Eggenreicha, K.; Zacha, E.; Beckb, H.; Wintersteiger, R. Determination of 4-amino-m-cresol and 5-amino-o-cresol by high performance liquid chromatography and fluorescence derivatization using fluorescamine. J. Biochem. Biophys. Meth. 2004, 61, 35-46.

8. Turesky, R.J.; Freeman, J.P.; Holland, R.D.; Nestorick, D.M.; Miller, D.W.; Ratnasinghe, D.L.; Kadlubar, F.F. Identification of Aminobiphenyl Derivatives in Commercial Hair Dyes. Chem. Res. Toxicol. 2003, 16, 1162-1173.

9. Sosted, H.; Rastogi, S.C.; Andersen, K.E.; Johanses, J.D.; Menne, T. Hair dye contact allergy: quantitative exposure assessment of selected products and clinical cases. Contact Derm. 2004, 50, 344-348.

10. Gosetti, F.; Chiuminatto, U.; Zampieri, D.; Mazzucco, E.; Marengo, E.; Gennaro, M.C. A new on-line solid phase extraction high performance liquid chromatography tandem mass spectrometry method to study the sun light photodegradation of mono-chloroanilines in river water. J. Chrom. 2010, 3427-3434. 
11. Lin, C.E.; Chen, Y.T.; Wang, T. Separation of benzenediamines, benzenediols and aminophenols in oxidative hair dyes by micellar electrokinetic chromatography using cationic surfactants. J. Chromatogr. A 1999, 837, 241-252.

12. Gioia, M.L.D.; Leggio, A.; Pera, A.L.; Liguori, A.; Napoli, A.; Perri, F.; Siciliano, C.; Determination by gas chromatography/mass spectrometry of $p$-phenylenediamine in hair dyes after conversion to an imine derivative. Chromatogr. A 2005, 1066, 143-148.

13. Tokuda, H.; Kimura, Y.; Takano, S. Determination of Dye Intermediates in Oxidative Hair-Dyes by Fused-Silica Capillary Gas-Chromatography. J. Chromatogr. 1986, 367, 345-356.

14. Pinheiro, H.M.; Touraud, E.; Thoma, O. Aromatic amines from azo dye reduction: Status review with emphasis on direct UV spectrophotometric detection in textile industry wastewaters. Dyes Pigments 2004, 61, 121-139.

15. Akyüz, M.; Ata, S. Simultaneous determination of aliphatic and aromatic amines in water and sediment samples by ion-pair extraction and gas chromatography-mass spectrometry. J. Chromatogr. A 2006, 1129, 88-94.

16. Akyüz, M. Simultaneous determination of aliphatic and aromatic amines in indoor and outdoor air samples by gas chromatography-mass spectrometry. Talanta 2007, 71, 486-492.

17. Shelke, M.; Sanghi, S.K.; Asthana, A.; Lamba, S.; Sharma, M. Fast separation and sensitive detection of carcinogenic aromatic amines by reversed-phase mu-liquid chromatography coupled with electrochemical detection. J. Chromatogr. A 2005, 1089, 52-58.

18. Mortensen, S.K.; Trier, X.T.; Foverskov, A.; Petersen, J.H. Specific determination of 20 primary aromatic amines in aqueous food simulants by liquid chromatography-electrospray ionizationtandem mass spectrometry. J. Chromatogr. A 2005, 1091, 40-50.

19. Brede, C.; Skjevrak, I.; Herikstad, H. Determination of primary aromatic amines in water food simulant using solid-phase analytical derivatization followed by gas chromatography coupled with mass spectrometry. J. Chromatogr. A 2003, 983, 35-42.

20. Wang, L.H.; Tsai, S.J. Simultaneous determination of oxidative hair dye p-phenylenediamine and its metabolites in human and rabbit biological fluids. Anal. Biochem. 2003, 312, 201-207.

21. Weis, T.; Angerer, J. Specific determination of aromatic amines in aqueous by liquid chromatography. J. Chromatogr. B 2002, 778, 179-192.

22. Grimmer, G.; Dettbarn, G.; Seidel, A.; Jacob, J. Detection of carcinogenic aromatic amines in the urine of non-smokers. Sci. Total Environ. 2000, 247, 81-90.

23. Ahlström, L.H.; Eskilsson, C.S.; Björklund, E. Determination of banned azo dyes in consumer goods. Trac-Trend Anal. Chem. 2005, 24, 49-56.

24. Ahlstöm, L.H.; Raab, J.; Mathiasson, L. Application of standard addition methodology for the determination of banned azo dyes in different leather types. Anal. Chim. Acta 2005, 552, 76-80.

25. Bhaskar, M.; Gnanamani, A.; Ganeshjeevan, R.J.; Chandrasekar, R.; Sadulla, S.; Radhakrishnan, G. Analyses of carcinogenic aromatic amines released from harmful azo colorants by Streptomyces SPSS07. J. Chromatogr. A 2003, 1018, 117-123.

26. Garrigós, M.C.; Reche, F.; Marín, M.L.; Jiménez, A. Determination of aromatic amines formed from azo colorants in toy products. J. Chromatogr. A 2002, 976, 309-317.

27. Oh, S.W.; Kang, M.N.; Cho, C.W.; Lee, M.W. Detection of carcinogenic amines from dyestuffs or dyed substrates. Dyes Pigments 1997, 33, 119-135. 
28. Mazzo, T.M.; Saczk, A.A.; Umbuzeiro, G.A.; Zanoni, M.V.B. Analysis of Aromatic Amines in Surface Waters Receiving Wastewater from a Textile Industry by Liquid Chromatographic with Electrochemical Detection. Anal. Lett. 2007, 10, 56-64.

29. Kissinger, P.T. Electrochemical Detectors. In Liquid Chromatography Detectors; Vickrey, T.H., Ed.; Marcel Dekker: New York, NY, USA, 1986; Volume 2, Chapter 4, pp. 125-164.

30. Kaliszan, R.; Marszałł, M.P.; Markuszewski, M.J.; Baczek, T.; Pernak, J. Suppression of deleterious effects of free silanols in liquid chromatography by imidazolium tetrafluoroborate ionic liquids. J. Chromatogr. A 2004, 1030, 263-271.

31. Buzzeo, M.C.; Evans, R.G.; Compton, R.G. Non-haloaluminate room-temperature ionic liquids in electrochemistry-A review. Chem. Phys. Chem. 2004, 5, 1106-1120.

32. Hapiot, P.; Lagrost, C. Electrochemical reactivity in room-temperature ionic liquids. Chem. Rev. 2008, 108, 2238-2264.

33. Zanoni, M.V.B.; Rogers E.I.; Hardacre, C.; Compton, R.G. The electrochemical reduction of the purines guanine and adenine at platinum electrodes in several room temperature ionic liquids. Anal. Chim. Acta 2010, 659, 115-121.

34. Marszałł, P.M.; Baczek, T.; Kaliszan, R. Reduction of silanophilic interactions in liquid chromatography with the use of ionic liquids. Anal Chim Acta 2005, 547, 172-178.

35. Sacher, F.; Lenz, S.; Brauch, H.J. Analysis of primary and secondary aliphatic amines in waste water and surface water by gas chromatography mass spectrometry after derivatization with 2,4-dinitrofluorobenzene or benzenesulfonyl chloride. J. Chromatogr. A 1997, 764, 85-90.

36. Chia, K.J.; Huang, S.D. Simultaneous derivatization and extraction of primary amines in river water with dynamic hollow fiber liquid-phase microextraction followed by gas chromatographymass spectrometric detection. J. Chromatogr. A 2006, 1103, 1580-1585.

37. Deng, C.; Li, N.; Wang, L.; Zhang, X. Development of gas chromatography-mass spectrometry following headspace single-drop microextraction and simultaneous derivatization for fast determination of short-chain aliphatic amines in water samples. J. Chromatogr. A 2006, 1131, 45-50.

38. Llop, A.; Pocurull, E.; Borrull, F. Automated determination of aliphatic primary amines in wastewater by simultaneous derivatization and headspace solid-phase microextraction followed by gas chromatography-tandem mass spectrometry. J. Chromatogr. A 2010, 1217, 575-581.

39. Akyuz, M.; Ata, S. Simultaneous determination of aliphatic and aromatic amines in water and sediment samples by ion-pair extraction and gas chromatography-mass spectrometry. J. Chromatogr. A 2006, 1129, 88-94.

40. Akyuz, M. Simultaneous determination of aliphatic and aromatic amines in ambient air and airborne particulate matters by gas chromatography-mass spectrometry. Atmos. Environ. 2008, 42, 3809-3819.

41. Namiesnik, J.; Jastrzebska, A.; Zygmunt, B. Determination of volatile aliphatic amines in air by solid-phase microextraction coupled with gas chromatography with flame ionization detection. J. Chromatogr. A 2003, 1016, 1-9.

42. Kaykhaii, M.; Nazari, S.; Chamsaz, M. Determination of aliphatic amines in water by gas chromatography using headspace solvent microextraction. Talanta 2005, 65, 223-228. 
43. Kamarei, F.; Ebrahimzadeh, H.; Yamini, Y. Optimization of solvent bar microextraction combined with gas chromatography for the analysis of aliphatic amines in water samples. J. Hazard. Mater. 2010, 178, 747-752.

44. Calero, A.M.; Pino, V.; Ayala, J.H.; González, V.; Afonso, A.M. Ionic liquids as mobile phase additives in high-performance liquid chromatography with electrochemical detection: Application to the determination of heterocyclic aromatic amines in meat-based infant foods. Talanta 2009, 79, 590-597.

45. Baizer, M.M.; Lund, H. Organic Electrochemistry: An Introduction and Guide, 3rd ed.; Marcel Dekker: New York, NY, USA, 1991; pp. 242-245.

46. Lee, H.S.; Choi, S.J.; Lee, H.M.; Jeong, C.K.; Kim, S.B.; Lee, J.T.; Yoo, S.D.; DeLuca, P.P.; Lee, C.K. Determination of salmon calcitonin in formulations by high-performance liquid chromatography with electrochemical detection. Chromatographia 1999, 50, 701-704.

47. Snyder, L.R.; Kirkland, J.J.; Glajch, J.L. Practical HPLC Method Development, 2nd ed.; John Wiley \& Sons, INC: New York, NY, USA, 1997; pp. 645-646.

Sample Availability: Samples of the hair dyes were available from the authors.

(C) 2012 by the authors; licensee MDPI, Basel, Switzerland. This article is an open access article distributed under the terms and conditions of the Creative Commons Attribution license (http://creativecommons.org/licenses/by/3.0/). 